\title{
La estructuración del territorio en la Bizkaia medieval: ensayo de interpretación
}

\author{
EnRiqueta Sesmero Cutanda \\ UNED Bizkaia \\ JAVIER EnRIQUEZ FERnÁnDEZ \\ Agirilan, S. L. \\ esesmero@portugalete.uned.es
}

RESUMEN

ABSTRACT

Frente a la idea habitual de que el agro de

Bizkaia estuvo tempranamente organizado, este artículo propone que la cuidadosamente dirigida conformación de

la red urbana durante los siglos XIII y XIV determinó la reorganización de dicha área, cuya administración primitiva es asimismo

analizada.

PALABRAS CLAVE

Poblamiento, Edad Media, urbanismo, administración.
Contrasting with the usual ideas about an early organisation of the biscaian countryside, this paper proposes that the carefufly directed creation of an urban netwok during the $x \|^{\text {th }}$ * XIV ${ }^{\text {th }}$ centuries brought about the reorganizating of that area, whose original administration is also discussed

KEYWORDS

Settlement, Middle Ages, Urbanism, Administration.

La historiografia vizcaína suele aceptar la mayor antigüedad de los municipios rurales o anteiglesias sobre las villas. La idea surgió en el siglo XVI a instancias de la Diputación en su larga confrontación por jurisdicción y límites con los concejos urbanos, y alcanzó singular transcendencia sociopolítica e institucional. Nuestro fin es criticarla, mostrando que la conformación del entramado urbano en los siglos XIII y XIV determinó, por reacción, la reestructuración espacial y administrativa del agro circundante. Aunque incidió en toda Bizkaia, no se trató de un fenómeno homogéneo, pues cada área generó especificidades. La escasez de documentos, casi inexistentes para el siglo xill y muy parcos para el XIV, obliga a comenzar por el período mejor conocido, para inferir los procesos 
anteriores ${ }^{1}$. Por ello, hemos optado por el ensayo, confiando en que un enfoque distinto de la evolución de nuestro territorio promueva investigaciones renovadoras.

\section{LAS FASES DE CONFORMACIÓN DE LA RED URBANA}

Antes de empezar, debemos indicar qué partes componian Bizkaia, pues sus límites actuales se fijaron a comienzos del xIX. El núcleo principal del Señorío -la "Tierra Llana», sujeta al Fuero clásico - comprendia, de oeste a este, la margen derecha y el curso medio del Ibaizábal, vía natural de Bilbao a Guipúzcoa; la "Bizkaia nuclear», con los valles de los ríos Butrón, Oca, Lea y Artibai, transversales a dicho corredor y a la mar; y el curso alto del Nervión y la cuenca del Arratia, transversales también, pero hacia Castilla. Más al oeste las Encartaciones, de fuerte personalidad, abarcaban una anfractuosa superficie formada por el valle de Salcedo, al sur; los Siete Concejos de Somorrostro, famosos por su excelente hierro; y el amplio valle de Carranza. Se integraron por completo en el Señorío en 1801 y, pese a su diversidad, mantuvieron instituciones y Fuero comunes hasta 1815. También los tuvo, al sureste, el Duranguesado, puerta hacia las Provincias alavesa y guipuzcoana. Al sur, el Valle de Orozco era un señorío de la casa Ayala, con la que disputó durante toda la Modernidad hasta unirse a Bizkaia en 1785. También al sur, entre Álava y Burgos y sin contacto directo con el Señorío, se ubican la ciudad de Orduña y su pequeño alfoz, vizcaínos desde al menos el siglo XIII.

Salpicando estos espacios encontramos veinte villas y una ciudad, articuladas de forma independiente a la naturaleza de cada uno. Surgidas en un lapso relativamente corto (1199-1376), responden a un elaborado plan promovido tanto por los señores del territorio -el linaje Haro- como por los reyes castellanos, señores desde Juan I. Su fin común, estructurar un espacio antes marginal pero que, por razones político-económicas, desde mediados del siglo xIII adquirió gran peso. Se siguió el modelo diseñado por la monarquía para Guipúzcoa, con pautas de las repoblaciones fronterizas: crear una serie de pequeños pero sólidos villazgos de evidente función urbana y con amplia jurisdicción, cuyo conjunto abarcase la totalidad del territorio. El éxito fue regular, pues Bizkaia contó desde la Baja Edad Media con un medio rural organizado y activo que acabó malogrando el proyecto inicial.

No hay unanimidad entre los especialistas sobre las fases del urbanismo vizcaíno. Nosotros distinguimos cinco. La primera abarca desde 1199, fecha de la

\footnotetext{
' Motivos: las desapariciones y el carácter consuetudinario de la foralidad. J. Enriquez participa como transcriptor en la Colección de Fuentes Medievales del País Vasco (San Sebastián: Eusko IkaskuntzaSociedad de Estudios Vascos, 1984-2003, 46 volúmenes y 3 en prensa); y, con E. Sesmero, en la edición de las Actas Históricas de las Juntas Generales de Bizkaia (Bilbao: Bizkaiko Batzar Nagusiak-Juntas Generales de Bizkaia, 1994-2003; 16 vol. y 8 en prensa), que, pese a comenzar en 1535, ofrecen referencias sobre la realidad precedente. Asimismo se han consultado numerosos libros municipales de Acuerdos y Decretos y de Elecciones, conservados en su mayoría en el Archivo Foral de Bizkaia, que no se especifican por falta de espacio.
} 
concesión de fuero a Valmaseda, a 1236, data extrema - no se conoce la exactade la fundación de la portuaria Bermeo. Comprendería la de Orduña, al pie de la ceja de la Meseta; la fallida de otro puerto, Plencia, salida del valle del Butrón; y quizá un primer intento en Bilbao. El objetivo sería reforzar un eje sur-norte mediante dos caminos que conectasen Castilla a través de Valmaseda y Orduña, que aún no pertenecian a Bizkaia, con el mar. Bilbao sería su punto intermedio: en su vado se unían ambas rutas para salvar el Ibaizábal. El fracaso en Plencia y la imposibilidad de crear Bilbao, en ambos casos por la oposición de la nobleza local (los "vizcainos" de la documentación) abrió un largo compás de espera.

El segundo momento es muy corto: los años ochenta del XIII. Es innegable el interés por fomentar las vías norte-sur hacia el mar. En el confín occidental de las Encartaciones, Lanestosa reforzó la dirigida a Laredo. En el centro-este se consolidaba la ruta Vitoria-Lequeitio gracias a Ochandiano, apoyo en el despoblado de la dura montaña de Urkiola, y a Durango y Errmua, en el fondo del valle. Estas dos servirian de extremo este a un nuevo eje: el paso hacia Guipúzcoa por el valle del Ibaizábal. Al otro encontramos la primera fundación documentada de Bilbao (ca. 1280 ), destino también del camino orduñés. El reforzamiento de éste generó una corta sub-etapa, en 1299-1300, con la refundación de Plencia y la reubicación de Bilbao en el paraje que ahora ocupa, más a propósito para el desarrollo económico... y para los intereses del conde don Diego López de Haro $V$, que gracias a su posición privilegiada como tutor de Fernando IV pudo imponer a la nobleza local sus pretensiones.

La tercera fase fue enteramente marinera y asimismo breve: el sexenio 1322 1327, datas fundacionales de Portugalete, en el Abra del Ibaizábal, y Ondárroa, en la desembocadura de! Artibai, con Lequeitio (1325), sobre la del Lea, como hito central $^{2}$. Ahora importaba consolidar la línea costera complementando a Bermeo y Plencia, y crear terminales a la conexión con el corredor central hacia Guipúzcoa. Portugalete ampararía la exportación del excelente hierro de los montes de Triano: por vía fluvial, hacia el interior del Señorío (el Barbadún, que bordea la cadena montañosa por el oeste, penetra en territorio encartado); por la marítima, hacia las ferrerias guipuzcoanas y hacia la Guyena de los Plantagenet, con quienes la Corona castellana mantenía relaciones político-comerciales.

La cuarta etapa resulta difusa, pues sus circunstancias políticas internas y externas - el turbulento reinado de Pedro I y las guerras civil y de los Cien Años- no eran idóneas. No obstante, se aprecia un importante cambio de miras. Las villas costeras habían fortalecido los viales primarios, con urbes separadas estratégicamente ente si seis leguas, es decir, una jornada a pie. Las nuevas pretendian fijar etapas a medio camino; potenciar las rutas secunaarias, coadyuvando a la humanización (poblamiento y explotación) del territorio; y fortificar ante posibles agresiones extranjeras los límites del Señorio, traspais de una Guipúzcoa demasiado

2 Al parecer, Ondárroa funcionaba como puebla ( $v$. el epígrafe 3) desde el XII, si no antes; Lequeitio pudo haber sido aforada en la segunda etapa. 
próxima a la guerra entre Francia e Inglaterra. Distinguimos tres momentos: los prolegómenos, con la fundación, en el valle de Arratia, de Villaro (1338), punto intermedio de otro camino entre Bilbao y Vitoria; el reforzamiento fronterizo, con Marquina (1355) y Elorrio (1356), a la vez descanso en las rutas a la costa y a Vergara; y un final caminero, en 1366, con Guernica (1366) asentada en el Bilbao-Bermeo, y Guerricáiz, intermedia en los de Durango-Lequeitio y DurangoOndárroa pero de escaso futuro por lo fragoso de su montuoso entorno.

El esfuerzo final se debió a Juan I, que al alcanzar el título de señor de Bizkaia, siendo todavía menor, autorizó en 1375 la fundación de Miravalles y en 1376 las de Munguía, Larrabezúa y Rigoitia. Todas ellas se ubican a mitad de viales existentes, con el fin, según la interpretación habitual, de protegerlos de los asaltos de los malhechores feudales banderizos. Sin embargo, en las tres últimas el reagrupamiento poblacional parece haber sido decisivo. Tal deducimos de la relevancia que otorgan sus cartas-puebla a los mortuorios (apenas mencionados en las demás salvo en Marquina), muestra del impacto de la crisis del Trescientos sobre la demografía vizcaína.

\section{LA DUDOSA EXISTENCIA DE MUNICIPIOS PREURBANOS}

Al tenor de lo dicho, nos planteamos cómo estaba organizada la población vizcaína antes de las villas y las repercusiones de éstas. La primera incógnita es muy difícil de resolver, pues las cartas-puebla son lacónicas. Sabemos que varias urbes de las tres fases iniciales existian previamente porque se expresa asi en los privilegios o porque se les concedió el patronazgo de sus iglesias matrices. Otras -Elorrio, Guernica, Marquina- surgieron ex nihilo sobre solares sin edificar o sobre mortuorios. Como era de esperar, todas recibieron un amplio territorio jurisdiccional, cuyos límites se detallaban con minuciosidad. Su enumeración nunca alude a entidades locales rurales y sólo en raras ocasiones se hacen vagas menciones a posibles agrupaciones supramunicipales.

Tal sucede en las dos cartas-puebla de Bilbao. Afirman que sus términos habían sido apeados con los de Çamudio e de alfoz d'Uribe. Es discutible si aquéllos fueron los miembros del poderoso solar de Zamudio o los vecinos de la localidad homónima, o si es un genérico para referirse a los habitantes del valle del Txorierri (donde ese pueblo se halla), colindante con la villa y pronto su secular abastecedor hortícola y ganadero, opción ésta que parece más factible. No menos equívoco es el término "alfoz" pues, que nos conste, es la única ocasión en que lo utilizan nuestros documentos medievales. Una hipótesis: como el escribano era vallisoletano, usó un concepto cercano a su realidad pero alejado de la vizcaína. Habría que equiparar "alfoz" a "merindad", que eso era a la postre Uribe: la merindad donde se asentó Bilbao. Después las definiremos.

En el comienzo de aforamiento, don Diego López de Haro afirmó que hacia en Biluao, de parte de Begoña, nueuamente poblaçion, fórmula repetida en el del con- 
de don Tello: fago en Guernica, de parte de Luno, poblacion e villa. Ello ha llevado a suponer que ambas urbes se indeperidizaron de localidades preexistentes. Nada lo sustenta. Las cartas nunca obviarian la importante existencia de entidades anteriores; las jurisdicciones se les adjudicaron sin inconvenientes y, además, se les concedió el patronato de sendas iglesias, Santa Maria de Begoña y San Pedro de Luno, luego también sus campaniles y feligreses. Más complejo es el caso de Miravalles-Ugao (1375), al que se trazaron límites colindantes con territorios aledaños a Bizkaia: tierra de Orozco, tierra de Llodio y tierra de Oquendo, en clara distinción frente al escueto "Arratia" —una de las merindades del Señorio- o el simple "Arrigorriaga", pueblo que un documento de 1373 define como concejo pese a que carecia de tal entidad juridica.

Una explicación sería la omisión deliberada, por parte del o los redactores de las cartas, de las localidades rurales englobadas en las villas, sobre todo si sus habitantes no estaban de acuerdo con la inclusión. Pero el proceso duró casi doscientos años, con una amplia casuística; las tipologías documentales de las cartaspuebla se repiten, pero nada forzaba a usar los patrones en el abierto campo de la fijación de límites. Quizá no existiesen entidades jurídicas municipales; de ahí las referencias a colectividades mayores. Aunque esta explicación refuerza nuestra propuesta, reconocemos que el silencio es justificable. En la institución de nuestros villazgos intervinieron otras voluntades, reflejadas en la expositio de algunas cartas poblacionales bajo la expresión con placer de los vizcaínos. Se ha interpretado que el promotor habría obtenido el beneplácito previo de la Junta General. Es posible; pero no se trataría de las Juntas Generales del Señorio, que no alcanzaron su plenitud hasta bien entrado el siglo XIV, sino de las de Merindad. Don Tello y el infante Don Juan justificaron las fundaciones de Marquina, Larrabezúa, Munguía y Rigoitia aduciendo la petición de las respectivas merindades. La de Miravalles, también del futuro Juan I, se hizo por petición expresa de los fixosdalgo como labradores de la comarca que dizen Zeberiano y principales beneficiarios. Todos sabían que una urbe conllevaba una revitalización económica y una redistribución territorial, poblacional y social que superaban su ámbito estricto. De ahi que la comarca entera se reuniese para sancionar su aparición y, también, la conveniencia de no citar a los municipios colindantes, perjudicados espacialmente por su creación.

Nosotros defendemos la inexistencia de municipios rurales asentados antes de las fundaciones urbanas. Nunca se mencionan en documentos contemporáneos a ellas en que nada justifica una ocultación intencionada. De hecho, hasta mediados del XIV no surge el concepto de anteiglesia, entidad local con jurisdicción administrativa y territorial propia. Por otro lado, las villas recibieron recursos económicos preexistentes, fundamentalmente montes y pastizales comunes, que se hicieron depender de las iglesias urbanas para garantizar su uso público y su inalienabilidad. Enseguida, el éxito de las urbes dinamizó sus entornos rurales, proveedores de materias primas, alimentos, combustible y aun transportistas (campesinos-carreteros estacionales). Los consiguientes aumento de población y crecimiento 
económico habrian movido a sus habitantes a desear ayuntamientos independientes e incluso la devolución de parte de los comunales perdidos. El movimiento se inició hacia el segundo tercio del XIV y concluyó sólo en 1630 gracias al tratado político de unión entre la Tierra Llana y las Villas y Ciudad, que hasta entonces habian mantenido Juntas separadas... e innumerables pleitos.

Nuestro mejor ejemplo es Lequeitio. Su carta de aforamiento le otorgó un amplio territorio boscoso, la ledanía de Amoredo ${ }^{3}$, cuyos pobladores serían vecinos de la villa aunque no residieran en ella. En un principio, Lequeitio se vio obligada a proteger su jurisdicción de las apetencias de sus vecinos: la ledanía de Aciro, la Merindad de Marquina y Ondárroa. Pero la fractura sería causada por sus propias feligresías rurales, que habian aumentado en habitantes y pujanza. La separación supuso un doloroso proceso, en el que se disputaba la propiedad de extensos montes caducifolios, carboneros y ganaderos. Cuando las primitivas aldeas cristalizaron en cuatro anteiglesias (Amoroto, Guizaburuaga, Ispáster y Mendeja), el contencioso se centró en lo eclesiástico, pues dicha propiedad había sido otorgada a la matriz de Santa María de Lequeitio; no se amortiguaría hasta que en 1519 las respectivas iglesias anejas fueran elevadas a parroquias.

Otros casos no fueron traumáticos. Ondárroa llegó a un acuerdo pacífico, ya entrado el XVI, con su lindera Berriatúa para dividirse los montes, parte de una antigua ledania. Guernica y Luno firmaron un convenio sobre la utilización de los montazgos comunes en 1451; la villa de Guerricáiz y sus vecinas Arbácegui y Cenarruza, en torno a 1430 ... Ni siquiera parece que importara a Bilbao que Begoña y Abando se le independizaran. Aparte de que ninguna le discutió sus montes, las oligarquías mercantiles bilbaínas, también terratenientes en el entorno, controlaban la producción de éste lo bastante como para eludir el conflicto, al menos en principio. En cambio, Miravalles nunca alcanzó pleno desarrollo porque gran parte de los labradores de Ceberio que la habían promovido se negaron a trasladarse a la urbe, constituyéndose como avecindados no residentes. La razón de esta complicada situación, origen de un contencioso aún no zanjado, fue el aprovechamiento de los montes, que los aldeanos se reservaron en su mayor parte para sí alegando su adscripción a la parroquia y sus propios derechos de casa solar o "foguera", despojando de su usufructo a la villa y al resto de los pobladores del valle, después constituidos en anteiglesia.

Las disputas continuaron hasta la Concordia de 1630, atizadas a menudo por las anteiglesias. Éstas habian logrado articularse en 1500 mediante la creación de un órgano representativo: la Diputación. Constituida orgánicamente como una villa más (dos diputados, doce regidores, dos sindicos), dirigió con firmeza el enfrentamiento hasta que ambas contendientes se avinieron, en parte extenuadas por las costas de un conflicto semiestancado, en parte quizá para contrarrestar la presión hacendística de la monarquía en tiempos duros para todos.

\footnotetext{
${ }^{3}$ Sobre las ledanias, véase el epigrafe 3.
} 


\section{LA ORGANIZACIÓN DEL ESPACIO RURAL PREURBANO}

Centrémonos ahora en cómo se organizaban el espacio y las gentes antes de la red urbana. Descartada la existencia de las anteiglesias, sólo nos quedan -y nos constan - las merindades, las ledanías, las pueblas, y entidades menores como barriadas y cofradias. Las trataremos por ese orden.

Poco se sabe de las merindades, unidades administrativas comarcales básicas. A su frente estaban los alcaldes del fuero, en número según su extensión, que conocian los pleitos civiles y criminales en primera instancia; y un merino para lo administrativo y policial. Su actividad nos consta desde el siglo XIII. Eran nombrados por el señor de Bizkaia, al que representaban y cuyos intereses defendían. Una junta de "vecinos", representaba los de la baja nobleza local y, en menor medida, los del campesinado frente a las pretensiones de los condes de Haro, y resolvia cuestiones administrativas y judiciales menores. Sobre las Juntas sólo quedan referencias a una reunión de la de Marquina hacia 1355 y alguna otra esporádica. Ello no merma su importancia: serían decisivas en la configuración de las Generales del Señorio, pilar del sistema foral moderno.

Las merindades gozaron de fueros consuetudinarios y ámbitos geográficos bien delimitados. La de las Encartaciones tenía su centro en Avellaneda (Sopuerta), su punto intermedio; el Duranguesado se reunía en Astola, desde el XIV sede de su tenencia de Corregimiento. En la Bizkaia nuclear hubo cinco. Arratia, la menos conocida, englobaba la cuenca del río homónimo; la de Marquina ocupaba el valle del Artibai; Busturia, los del Lea y Oca; Uribe estaba a caballo entre los del Butrón y los tramos bajos del Nervión e Ibaizábal. El trecho medio de éste, más compartimentado, albergó otras dos, pequeñas. La de Zornoza, a caballo entre los cauces medio del lbaizábal y alto del Oca, controlaria una zona de transición y unión de prácticamente las cinco. Una sexta, la de Bedia, parece tardía (no se alude antes de! XVI); es muy posible que se debiese a los intereses de Bilbao en la zona, donde poseía numerosos campesinos adscritos. Por desgracia, desconocemos cómo se articulaban las merindades, el grado de analogía con sus homólogas castellanas, sus competencias y su evolución inicial, ya que su fin vino de la conformación de las Juntas Generales, que las hizo desaparecer pese que nada movia al conflicto con ellas.

Las ledanías eran de menor entidad jurídica, si bien relevantes en lo económico. Consistían en la agrupación de localidades para aprovechar en proindiviso montes, seles y pastizales que se hacian depender de una parroquia matriz para evitar ambiciones particulares o, lo más plausible, por una arraigada y remotísima tradición religiosa ${ }^{4}$. Es significativo que sólo se citen en el cuadrante NE de Bizkaia, en las Merindades de Uribe y Marquina (son demasiado dudosas en la de Durango). Esto puede deberse al vacio documental $o$, mejor, a que sólo existiesen en

${ }^{4}$ Ledania < litania, pero la adscripción inicial no está clara en todos los casos. 
aquéllas, pues nada obsta para que en áreas similares se diera la misma organización poblacional y administrativa. El motivo, su quebrada orografía y su economía ganadera. En cambio, la agricultura vizcaína se desarrolló inicial y principalmente en valles amplios y de fácil comunicación, en las Merindades de Uribe, Arratia y Orozco y en menor medida en la duranguesa; no por casualidad Orozco y Uribe sufrieron un intenso proceso feudalizador, algo menor en las otras dos.

La citada ledanía de Amoredo, en torno a Lequeitio, parece haber sido la mayor y una de las primeras en desaparecer. La de Aciro, su inmediata al SE, estaba formada por Murélaga, Ereño y Navárniz y fue la última en desintegrarse, a mediados del siglo XVII, cuando se repartieron los montazgos. Al Este quedaba la que aglutinaba Ondárroa y Berriatúa, y muy probablemente la Merindad de Marquina fue conformada en torno a otra. Ocupando las estribaciones norteñas del Oiz estaba la que reunía a Guerricáiz, Arbácegui-Munitibar y Cenarruza. La de Guernica y Luno, con el "concejo" de Ajánguiz - llamado «ledanía» en el xvII- sería el probable centro de una que controlara las fértiles vegas de pasturaje del curso mediobajo del Oca.

Observemos Aciro, sita entre el corazón de la Bizkaia nuclear, sinuoso y de difícil salida a la mar o el corredor del Ibaizabal, y la amena bocana de Urdaibai. Administraba los pastos veraniegos y los extensos bosques del lluntzar, centro del cuadrante NE vizcaíno. Elevado $(727 \mathrm{~m})$ para su entorno, permitía las transterminancias del productivo ovino, variar la alimentación del esencial vacuno, y proporcionar a los habitantes de zonas bajas carbón vegetal y subproductos silvícolas. No por casualidad en esa atalaya se ubicó un castro celta. Aunque las primeras citas muestran a Aciro como ente supralocal, la reunión de tres anteiglesias, es plausible el fenómeno inverso: la superposición de los municipios de Ereño, Navárniz y Murélaga al indiviso original, bien por separación de la población derechohabiente a él para reunirse administrativamente con las cercanas en cotas inferiores, bien por avance de las jurisdicciones establecidas por éstas hacia la riqueza de los altos.

La organización acirotarra remite a una lejana humanización territorial. Navárniz estaba dividida en “amarrecos» ('decenas'), unidades dezmatorias. Esta pervivencia de la primitiva organización eclesial es única en Bizkaia y pudo deberse a su asentamiento de montaña, que siempre limitó su expansión física y demográfica. La distancia media entre las unidades poblacionales de Aciro, menores o mayores, y entre éstas y sus templos es de unos $6 \mathrm{~km}$, formando una retícula de etapas de ida y vuelta en el día, adecuadas para un intercambio regular a pie o con el pesado carro boyar de transporte a través de una zona de geografía incómoda y con poca población y, por tanto, no muy segura para viajar.

Corrobora la plausible organización uniforme del área NE la presencia de pueblas, física, funcional y poblacionalmente urbanas pero carentes de reconocimiento jurídico. Cabe pensar en la traducción castellana - nunca se escribía en euskera- de la denominación dada por las gentes a un núcleo compacto con res- 
pecto a su entorno. No lo creemos, porque resultan asociadas a ledanías. Lequeitio y Ondárroa lo fueron antes de ser elevadas de categoria; Aciro contaba con la de Aulestia y la zona del Oiz con la de Bolíbar. Guernica no existía antes de su fundación: ¿fue Ajánguiz la puebla? La Merindad de Busturia tuvo a las portuarias Mundaca, en la bocana del mismo río, y Ea, en la de su homónimo, y es factible la existencia de ledanías en torno a ellas. Características comunes de las pueblas: se situaban en el fondo de valles cerrados, junto a vados de ríos y sobre caminos secundarios pero importantes, y aglutinaban superficies y poblaciones amplias en términos relativos.

En nuestra contra juegan la falta de pueblas en la Merindad de Marquina, por muy cerca que esté Bolíbar; y la existencia fuera del área de dos que no contaron, que se sepa, con nada similar a una ledanía: Zubiaur de Zornoza en Amorebieta, centro socioeconómico de la Merindad de Zornoza, e lbaizábal en Bilbao. Se trata de valles no muy cerrados, por lo que el equilibrio entre las actividades agrícolas y ganaderas fue mayor; además, sus caminos eran primordiales (el guipuzcoano y el castellano), lo que favoreció el comercio y la aparición de un artesanado metalúrgico especializado. No constan pueblas en las Encartaciones. Al igual que en las merindades orientales, priman las zonas abruptas y de valles cerrados, donde prevalecian las actividades ganaderas y forestales salvo en su franja sur, de orientación agrícola y estructura poblacional similares a las de Busturia y Marquina. Sin embargo, sufrieron un intenso proceso feudalizador, quizá por el deseo de las clases dominantes de controlar sus minas, lo que obstaculizaría crear entes semiurbanos.

¿Fueron las pueblas ensayos de fundación de villas? Está claro en Lequeitio y Ondárroa, por ser puertos. Pero están muy cercanas: ¿y en el resto? Ibaizábal fue antecedente inmediato de Bilbao. Ferrerías, molinos y el arranque de los caminos hacia Guipúzcoa y Castilla por el Nervión la animaban ya a fines del XIII, cuando menos. Aunque para fundar se acabó escogiendo un vado kilómetro y medio aguas abajo, a la entrada de un meandro que conformaba una amplia plataforma fácil de aterrazar, Ibaizábal mantendría su dedicación, dependiendo de la nueva urbe. Zubiaur estaba, como dice su nombre, 'ante el puente' de un estratégico vado del Ibaizábal medio. Su situación en el cruce de las vias a Guipúzcoa y el Cantábrico por Guernica la convertiría en punto de partida de una constante exportación comarcal de productos del vacuno y de primera fusión del hierro. Mundaca fue en la Modernidad la primera localidad llamada a Juntas Generales por la Merindad de Busturia, que precedía a sus homólogas. El orden de llamamiento de villas indicaba cierta prelación, de ahí los pleitos entre algunas en el XVII, celoso de honras y preeminencias; pero fuera de Bermeo, Bilbao y Durango, cabezas de tercio ${ }^{5}$, no respondía a criterios demográficos ni de antigüedad, por lo que no cabe extrapolarlos. ¿Se quiso apoyar a Bermeo - a $3 \mathrm{~km}$ escasos por tierra- o competir con

5 División altomoderna de las villas y ciudad para ciertas gestiones administrativas y convocar sus juntas 
él? Aunque el puerto mundaqués fuese reducido para el comercio, significativo para los bermeanos junto a su famosa pesca, era de acceso más directo a la mercantil Guernica... No hay ni una alusión al respecto.

Las unidades básicas de poblamiento, organización y producción eran las barriadas, puñados de caseríos más o menos dispersos en función de la orografía. Se aglutinaban en torno a una advocación religiosa, en una ermita o iglesia sufragánea de la parroquia de una entidad superior, generalmente una villa. Se desconoce si poseian entramado administrativo propio. Más tarde se insinúa la existencia de asambleas de los dueños (¿y/o?) cabezas de familia de caseria; entenderian sobre aprovechamiento forestal, obras comunitarias y representación municipal. Lo religioso era evidente en las cofradías. Primaban en Arratia y el Duranguesado, montuosos y silvopecuarios al par que esenciales camineros. Aparte de gestionar los montes cofradiales, en la Modernidad servirian al nombramiento de los electores que designaban los candidatos a la insaculación para el fielato (en las anteiglesias, cargo similar a la alcaldia). Se mantuvieron como células inframunicipales fuertes hasta el fin de la foralidad en 1876, por el papel que acordaban a las casas de foguera entera... y sus dueños. Nada de ello nos consta para el Medievo.

Para concluir, dos trazos de conjunto. La conformación territorial de la Bizkaia medieval estuvo muy condicionada por las potencialidades económicas. El elemento de base fue idéntico, la barriada; divergen los entes superiores. Al NW del área nuclear, de amplios valles y predominio agrícola, la profunda implantación de la nobleza local suprimió los organismos supralocales medios de origen remoto, imponiendo el tipo administrativo del norte de Castilla, la merindad. Ledanías y cofradías pervivieron en la zona nororiental, que dependía del bosque y la ganadería. La aparición de las villas, en cierto modo auspiciadas por las ledanias, significó un importante motor de cambio económico, poblacional y administrativo que terminaria poniendo fin al primitivo sistema. 